\title{
Primary pulmonary Langerhans cell histiocytosis associated with smoking in an adolescent boy
}

\author{
Elvan Çağlar Çıtak ${ }^{1}$ Erdem Ak¹, Fatih Sağcan², Yüksel Balc1², Rabia Bozdoğan-Arpac1 ${ }^{4}$, \\ Necdet Kuyucu ${ }^{5}$ \\ Divisions of ${ }^{1}$ Pediatric Oncology and ${ }^{5}$ Pediatric Infectious Disease, Departments of ${ }^{2}$ Pediatrics, ${ }^{3}$ Radiology and ${ }^{4}$ Pathology, \\ Mersin University Faculty of Medicine, Mersin, Turkey. E-mail: caglarcitak@yahoo.com \\ Received: 22th December 2016, Revised: 14th February 2017, Accepted: 20th February 2017
}

\begin{abstract}
SUMMARY: Çıtak EÇ, Ak E, Sağcan F, Balcı Y, Bozdoğan-Arpacı R, Kuyucu N. Primary pulmonary Langerhans cell histiocytosis associated with smoking in an adolescent boy. Turk J Pediatr 2017; 59: 586-589.

Pulmonary Langerhans cell histiocytosis (PLCH) is a well known entity in adults but is exceedingly rare in children. It is better described in adults than in children. Smoking is a major etiological factor in adulthood. We report a case of a previously healthy 16-year-old male with a history of cigarette smoking, who presented with cough with sputum, breathlessness, easy fatigability and loss of appetite for two weeks. He was first diagnosed with bronchiectasis according to the cystic pulmonary changes demonstrated by computed tomography. After appropriate treatment, there was no sign of clinical improvement. A lung biopsy confirmed Langerhans cell histiocytosis (LCH). The definitive diagnosis was isolated pulmonary LCH. PLCH should be considered in the etiology of cystic lung diseases. Isolated pulmonary LCH is rare so such cases are needed to be reported and followed-up to understand the treatment response and course of this illness.
\end{abstract}

Key words: Langerhans cell histiocytosis, children, smoking, pulmonary involvement.

Langerhans cell histiocytosis ( $\mathrm{LCH}$ ) is a rare disease characterized by abnormal infiltration of organs by the Langerhans cell, a type of dendritic cell, with surface expression of CD1a receptor. ${ }^{1}$ In adults, pulmonary involvement is more common in $\mathrm{LCH}$, where it may present as isolated lung involvement or as a part of multisystem disease, and is seen almost exclusively in smokers. In children, it has been reported that pulmonary involvement in the context of multisystem LCH may not be an adverse prognostic factor. ${ }^{2}$ However, isolated pulmonary $\mathrm{LCH}(\mathrm{PLCH})$ in children is extremely rare and therefore it is not yet clear whether it has a better or worse outcome than in adults. Smoking related PLCH is very rare in childhood. To our knowledge five cases of PLCH were reported in childhood due to smoking. Three of them were active smokers, and two of them were reported as a result of second hand smoking. ${ }^{3-6}$ We now present a rare case of severe PLCH in an adolescent boy who smokes.

\section{Case Report}

A 16-year-old boy was admitted to the hospital with cough with sputum, breathlessness, easy fatigability and loss of appetite for two weeks without hemoptysis, chest pain and joint pain. He did not have a medical history of tuberculosis or contact with patients with tuberculosis. His history revealed that he had been smoking a pack of cigarettes per day for the past five years and he did not consume alcohol. He had stopped smoking before admission. Chest X-ray showed indistinct vessel margins and cystic changes (Fig. 1a). The patient was admitted to the department of pediatric infectious diseases, received antibiotic therapy for bronchiectasis, but there was no sign of response to treatment. In further investigation, sputum for acid fast bacilli (AFB) and tuberculin were analyzed and they were negative. On physical examination, he was febrile $\left(38.5^{\circ} \mathrm{C}\right)$ with pulse rate of $88 /$ minute, respiratory rate of $26 /$ minute and blood pressure of 90/60 $\mathrm{mmHg}$. He had no 
evidence of lymphadenopathy or clubbing. On examination of respiratory system, crackles were heard in bilateral bases. On the day of admission CBC showed hemoglobin of $11.2 \mathrm{~g} /$ $\mathrm{dl}$, total leukocyte count of $8,400 / \mathrm{mm}^{3}$ with neutrophil predominance. The coagulation profile, renal and liver function tests were normal. Anti-nuclear antibodies and rheumatoid factor, $\alpha 1$ antitrypsin, sweat test were negative. C-reactive protein $(8 \mathrm{mg} / \mathrm{L})$ was positive. On thorax $\mathrm{CT}$, thin walled diffuse lung cysts were seen. The cysts were predominantly located in upper and middle lung zones, relatively sparing the lung bases (Fig. 1B). The patient was lost to follow-up for one year. When he visited the hospital one year after the treatment of bronchiectasis, a thorax CT was performed. On CT the cysts were coalesced and enlarged (Fig. 1C). There were consolidations around some of the cysts, presumed to be inflammatory in origin. Mild parenchymal destruction was also seen. In view of thorax CT findings, a provisional diagnosis of LAM (Lymphangioleiomyomatosis) and PLCH was considered. Pulmonary function tests were as following: forced expiratory volume in 1 second, forced vital capacity, lung volumes, and diffusion capacity were all reduced consistent with a restrictive ventilatory defect. Wedge biopsy was performed from the right lung. We confirmed LCH with CD 1a and S100 positivity on immunohistochemistry (Fig. 2. a,b,c). Whole body bone survey, bone scintigraphy, cervical and abdominal USG were performed for other systemic involvements of $\mathrm{LCH}$, all were normal. Urinary density was 1010 and it was investigated for diabetes insipitus.

He was started on prednisolone and weekly vinblastine for 6 weeks then weekly vinblastine for 6 weeks and 3 days a week prednisolone for 6 weeks according to the Histiocyte Society Treatment Guidelines 2009.7 He was symptom
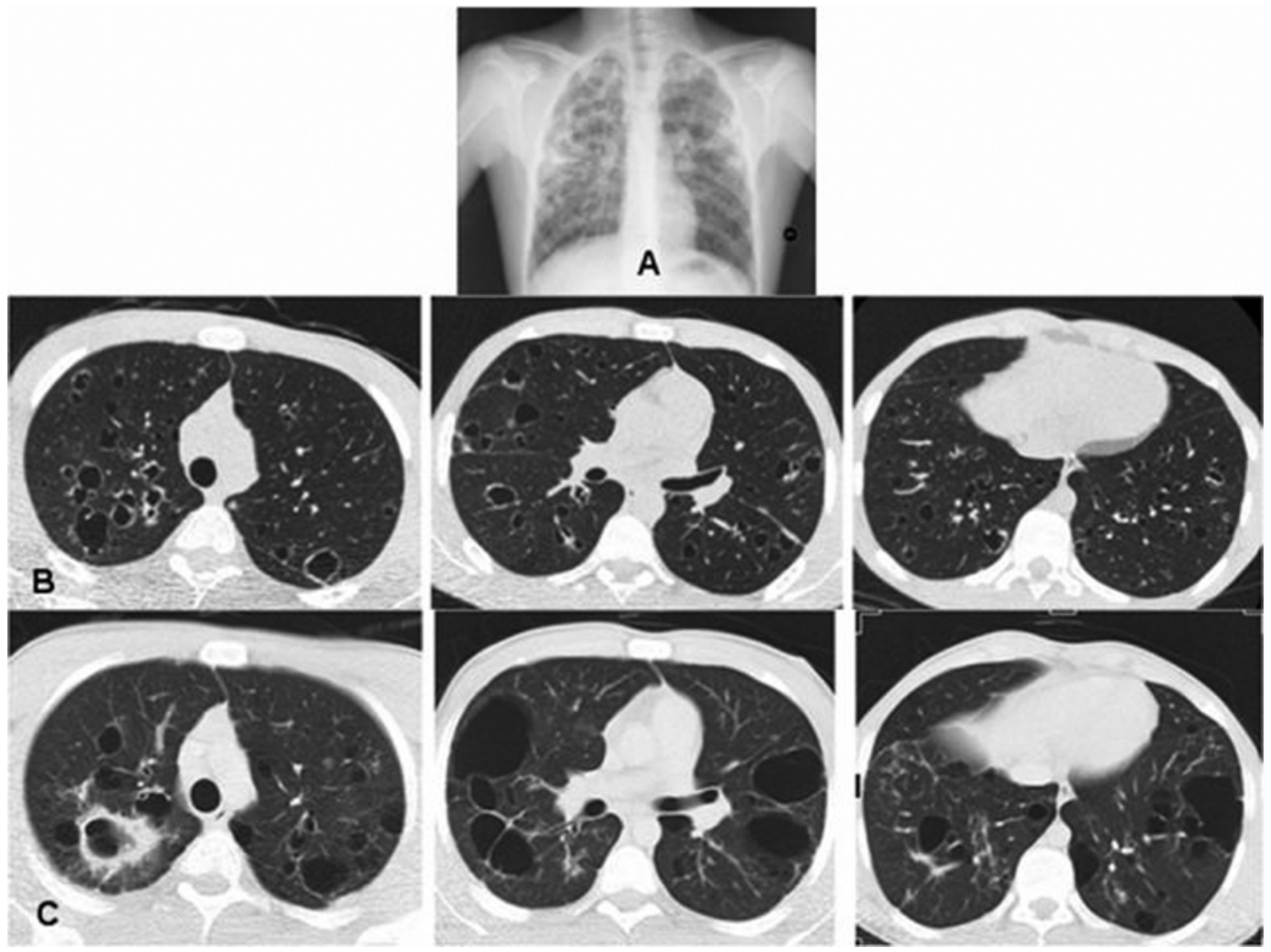

Fig. 1. A. Chest X-ray showing indisitinct vessel margins and cystic changes, B. Thorax CT examination showed numerous lung cysts, predominantly located in upper and middle lung zones, relatively sparing the lung bases, C. Thorax CT examination after 2 years, coalescence and enlargement in the cysts, with pericystic inflammation in the right upper lobe. 


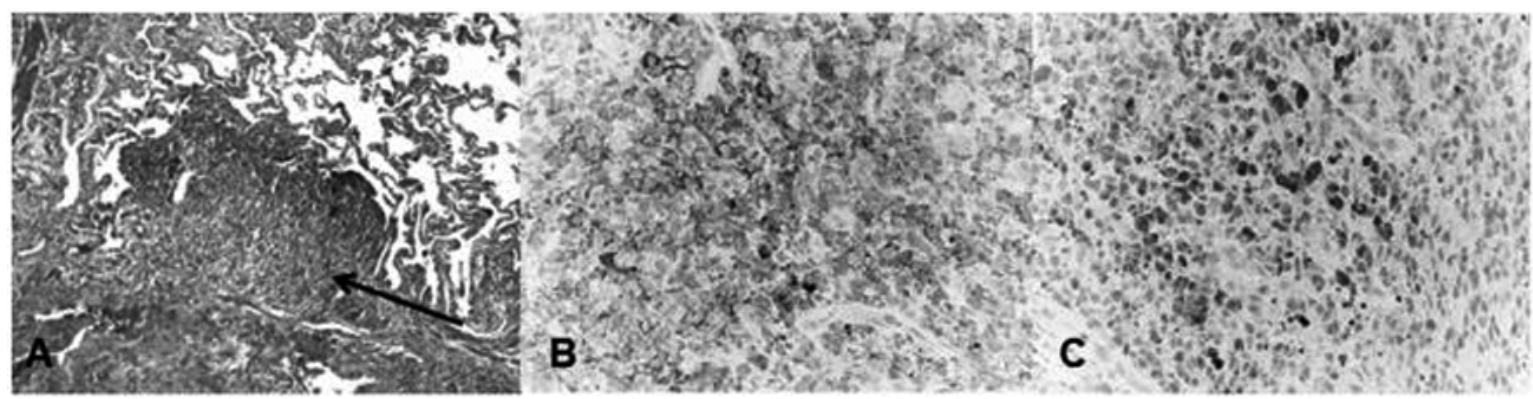

Fig. 2. A. Histopathology specimen showing lung parenchyma with focal of polygonal cells with vesicular indented cleaved nuclei, prominent eosinophilic cytoplasm (arrow) typical of a Langerhans cell histiocyte (H-E, X100), B. Cytoplasmic CD1a positivity in the histiocytic cells (CD1a, x400), C. Cytoplasmic S100 positivity in the histiocytic cells (S100, x400).

free but after initial treatment new lesions were documented by thorax CT. Moreover, the obstructive pattern was also seen in pulmonary function test. According to the protocol he had an active disease (progression of signs or symptoms and/or appearance of new lesions) and according the definition of response criteria he had an intermediate response. So, we decided to change the treatment to 2-chlorodeoxyadenosine and cytosine arabinoside (Ara-C). After four cycles of treatment, he was symptom free and thorax CT was stable. Pulmonary function test was better than before salvage treatment. On thorax CT there was no new lesions. We decided to follow without treatment. He has been symptom free for 5 years. Written informed consent was obtained from the patient's parents for publication.

\section{Discussion}

The majority of adult patients with pulmonary involvement by $\mathrm{LCH}$ are limited to the lung8 . The disease in adults stabilizes clinically and radiologically in approximately $50 \%$ of patients, whereas it may resolve spontaneously in $25 \%$ of the cases. ${ }^{1,9}$ In the remaining $25 \%$ of patients a progressive disease develops resulting in diffuse cystic lung destruction. In a small minority of cases death results from respiratory insufficiency or pulmonary hypertension. ${ }^{8-10}$ As opposed to adults, pulmonary involvement in children mostly occurs as part of a multisystemic form of $\mathrm{LCH}$ where it is present in $23 \%$ to $50 \%$ of cases; lung involvement is rarely the most predominant clinical manifestation. ${ }^{11}$ Isolated pulmonary involvement is extremely rare in children mainly due to two reasons: first, this condition is mainly associated with the effects of cigarette smoke, which is less expected in children, unless there is a history of passive smoking. Second, although the isolated form of PLCH may begin in childhood, it may remain clinically asymptomatic and does not get diagnosed until adulthood. ${ }^{12,13}$ Few cases of confirmed isolated PLCH have been reported in literature in the pediatric age group. $2,5,8,14-16$ In only two of them with eventually stabilized disease. Our patient was symptomatic at the beginning. The Histiocyte Society Evaluation and Treatment Guidelines April 2009 provide definition of the clinical categories, treatment protocols and assessment of treatment response and response criteria, which can be used for reference. He received prednisolone and vinblastine treatment according to this guideline. After initial and second course of therapy he was symptom free but radiological findings continued. So, we changed his treatment to 2-chlorodeoxyadenosine and cytosine arabinoside but radiologically there was no change after the treatment. We decided to follow without treatment.

How tobacco contributes to the development of pulmonary $\mathrm{LCH}$ lesions remains unknown. It has been suggested that an altered immune response to tobacco glycoprotein may stimulate lymphocyte activation by cytokine production to induce local Langerhans cell proliferation and activation. It has been shown that tobacco glycoprotein is a potent stimulator of macrophages, inducing the production of interleukin- 1 and interleukin- 6 cytokines. ${ }^{17}$ Another hypothesis is that the development of hyperplastic or dysplastic bronchiolar lesions may be involved in both the accumulation and the activation of Langerhans cells in bronchioles. ${ }^{6}$ This would explain the bronchiole- 
centered distribution of the lesions. The primary lesion is a peribronchiolar granuloma causing interstitial lung disease.

In the literature smoking associated PLCH was described in childhood very rarely; to our knowledge only 6 cases were described including ours. Three of them had stable disease including ours.

In conclusion; second hand or active smoking could cause a PLCH in childhood. For this reason, exposure to second hand smoke must be avoided as well as cigarette smoking in adolescents. Measures should be implemented to prevent it from becoming attractive. Although rare, when air cysts and bronchiectasis on chest $\mathrm{X}$-ray, are observed, PLCH should come to mind in the differential diagnosis.

\section{REFERENCES}

1. Suri HS, Yi ES, Nowakowski GS, Vassallo R. Pulmonary Langerhans cell histiocytosis. Orphanet J Rare Dis 2012; 7: 16.

2. Braier J, Latella A, Balancini B, et al. Outcome in children with pulmonary Langerhans cell histiocytosis. Pediatr Blood Cancer 2004; 43: 765-769.

3. Nakhla H, Jumbelic MI. Sudden death of a patient with pulmonary Langerhans cell histiocytosis. Arch Pathol Lab Med 2005; 129: 798-799.

4. Okubo F, Miyazaki E, Ono E, et al. A case of pulmonary Langerhans cell histiocytosis presenting disappearance of coalescing air wall cysts after smoking cessation. Nihon Kokyuki Gakkai Zasshi 2005; 43: 432-436.

5. Nagy B, Soos G, Nagy K, Dezso B. Natural course of isolated pulmonary Langerhans' cell histiocytosis in a toddler. 3-year follow-up. Respiration 2008; 75 : 215-220.

6. Adams EP, Sauceda D, Oliver J, Cecalupo A. Isolated pulmonary Langerhans cell histiocytosis in a 17-yearold male. J Pediatr Hematol Oncol 2007; 29: 121-124.

7. Langerhans cell histiocytosis, Histiocyte society Evaluation and Treatment Guidelines. Available at: https://histiocytesociety.org/document.doc?id=290 (Accessed April 2009)

8. Howarth DM, Gilchrist GS, Mullan BP, Wiseman GA, Edmonson JH, Schomberg PJ. Langerhans cell histiocytosis: Diagnosis, natural history, management, and oucome. Cancer 1999; 85: 2278-2290.

9. Vassallo R, Ryu JH, Colby TV, Hartman T, Limper AH. Pulmonary Langerhans'-cell histiocytosis. N Engl J Med 2000; 342: 1969-1978.

10. Vassallo R, Ryu JH, Schroeder DR, Decker PA, Limper AH. Clinical outcomes of pulmonary Langerhans'-cell histiocytosis in adults. N Engl J Med 2002; 346: 484490.
11. Smets A, Mortelé K, de Praeter G, Francois O, Benoit Y, Kunnen M. Pulmonary and mediastinal lesions in children with Langerhans cell histiocytosis. Pediatr Radiol 1997; 27: 873-876.

12. Aydin GB, Kibar E, Han U, Kale Y, Aslan A, Kose G. Pulmonary Langerhans cell histiocytosis in an infant: Can passive smoking accelerate the disease progress? Pediatr Pulmonol 2007; 42: 565-567.

13. Aydoğdu K, Günay E, Fındık G, et al. Pulmonary Langerhans cell histiocytosis; characteristics of 11 cases. Tuberk Toraks 2013; 61: 333-341.

14. Schulze J, Kitz R, Gruttner HP, Schmidt H, Zielen S. Severe isolated pulmonary Langerhans cell histiocytosis in a 6-year-old girl. Eur J Pediatr 2004; 163: 320-322.

15. Braier J, Latella A, Balancini B, Castanos C, Goldber J. Isolated pulmonary Langerhans cell histiocytosis presenting with recurrent pneumothorax. Pediatr Blood Cancer 2007; 48: 241-244.

16. Kanik-Yuksek S, Ozkaya-Parlakay A, Gulhan B, et al. A rare diagnosis in children: Isolated pulmonary langerhans cell histiocytosis. Clin Respir J 2018; 12: 355-356.

17. Youkeles LH, Grizzanti JN, Liao Z, Chang CJ, Rosenstreich DL. Decreased tobaccoglycoproteininduced lymphocyte proliferation in vitro in pulmonary eosinophilic granuloma. Am J Respir Crit Care Med 1995; 151: 145-150. 